\title{
Hypolipidaemic and antioxidative effects of oligonol, a low-molecular-weight polyphenol derived from lychee fruit, on renal damage in type 2 diabetic mice
}

\author{
Jeong Sook Noh ${ }^{1}$, Hyun Young $\mathrm{Kim}^{2}$, Chan Hum Park ${ }^{1}$, Hajime Fujii ${ }^{3}$ and Takako Yokozawa ${ }^{1}$ \\ ${ }^{1}$ Institute of Natural Medicine, University of Toyama, 2630 Sugitani, Toyama 930-0194, Japan \\ ${ }^{2}$ Department of Food Science, Jinju National University, 150 Chilamdong, Jinju 660-758, Korea \\ ${ }^{3}$ Amino Up Chemical Co., Ltd, 363-32 Shin-ei, Kiyota-ku, Sapporo 004-0839, Japan \\ (Received 2 November 09 - Revised 25 March 10 - Accepted 26 March 10 - First published online 20 July 2010)
}

Oligonol was orally administered at 10 or $20 \mathrm{mg} / \mathrm{kg}$ body weight per $\mathrm{d}$ for 8 weeks to $d b / d b$ mice with type 2 diabetes, and its effects were compared with those of the vehicle in $d b / d b$ and $\mathrm{m} / \mathrm{m}$ (misty, non-diabetic) mice. Serum and renal biochemical factors, protein expressions related to lipid metabolism and inflammation, and advanced glycation endproducts were measured. There were significant reductions in the serum lipid concentration, reactive oxygen species (ROS) and lipid peroxidation, as well as improvements in renal function parameters. In addition, oligonol treatment significantly decreased ROS levels and lipid peroxidation in the kidney. In particular, the renal lipid contents such as TAG and total cholesterol were significantly reduced in the oligonol-administered groups through the up-regulation of PPAR $\alpha$ and down-regulation of sterol regulatory element-binding protein-1 in $d b / d b$ mice. Moreover, oligonol inhibited non-fluorescent AGE formation and their receptor expression, suggesting that it could effectively inhibit AGE development caused by oxidative stress and/or dyslipidaemia in the kidney of $d b / d b$ mice. Furthermore, augmented expressions of NF-кBp65, cyclo-oxygenase- 2 and inducible NO synthase were down-regulated to the levels of $m / m$ mice in the group given oligonol at $20 \mathrm{mg} / \mathrm{kg}$. This means that oligonol would act as a regulator in the inflammatory response of type 2 diabetes. The present results suggest that oligonol could have renoprotective effects against abnormal lipid metabolism and ROS-related AGE formation in type 2 diabetes.

Oligonol: Type 2 diabetes: Renoprotective effects

Diabetes is associated with oxidative stress and inflammation due to hyperglycaemia and hyperlipidaemia. Hyperglycaemia and dyslipidaemia induce the generation of free radicals, inflammatory responses and oxidative stress reactions, leading to the complications and mortality associated with obesity and type 2 diabetes. Hyperglycaemia causes oxidative stress due to increased mitochondrial production of the superoxide anion, non-enzymic glycation of proteins, and glucose auto-oxidation. In the absence of an appropriate compensatory response from the endogenous antioxidant network against gluco- and lipotoxicity caused by hyperglycaemia and hyperlipidaemia under diabetes, oxidative stress becomes marked, leading to activation of the stress-sensitive intracellular signalling pathway ${ }^{(1,2)}$. In addition, hyperglycaemia accelerates the formation of advanced glycation endproducts (AGE) which are proteins produced from non-enzymic glycation reactions ${ }^{(3)}$. AGE induce free radical formation, accumulate during the normal ageing process and at accelerated rates during the course of diabetes, and are associated with the pathogenesis of chronic diseases such as arthritis, atherosclerosis, liver cirrhosis and diabetic nephropathy ${ }^{(4)}$.
In particular, there is a strong correlation between AGE accumulation and the presence and severity of diabetic kidney disease ${ }^{(5)}$. Moreover, type 2 diabetic individuals almost invariably show a marked disruption of lipid dynamics, often reflected by elevated levels of circulating NEFA and TAG, together with excess fat deposition in various tissues. Accordingly, to prevent diabetic renal damage associated with structural and functional changes, oxidative stress and/ or inflammation, it is important to reduce the development of AGE even in the absence of normalising glucose or lipid levels $^{(6)}$.

Oligonol, which is now available commercially as a new dietary ingredient, is an optimised phenolic product derived from lychee fruit polyphenols containing catechin-type monomers and low-molecular-weight oligomers ${ }^{(7)}$. Based on recent studies, there is accumulating evidence that oligonol can induce some physiological and biochemical alterations in vitro and in vivo, such as the induction of apoptosis in cancer cells ${ }^{(8)}$, antioxidant and anti-inflammatory effects in mice ${ }^{(9)}$, and beneficial subjective effects on the feeling of fatigue in young athletes ${ }^{(10)}$. Moreover, the oral administration

Abbreviations: AGE, advanced glycation endproducts; CEL, $N^{\varepsilon}$-(carboxyethyl)lysine; CML, $N^{\varepsilon}$-(carboxymethyl)lysine; COX-2, cyclo-oxygenase-2; GSH, reduced glutathione; GSSG, oxidised glutathione; INOS, inducible NO synthase; RAGE, receptor for advanced glycation endproducts; ROS, reactive oxygen species; SREBP, sterol regulatory element-binding protein; TBARS, 2-thiobarbituric acid-reactive substances.

* Corresponding author: Dr Takako Yokozawa, fax +81 76415 8841, email yokozawa@inm.u-toyama.ac.jp 
of oligonol improves the regulation of genes for adipokines in white adipose tissue of mice on administering a high-fat diet ${ }^{(11)}$. Indeed, the dietary feeding of proanthocyanidins, which comprise oligonol, has been reported to induce a significant attenuation of tissue fat levels, without changing the total body mass of animals compared with non-proanthocyanidin-fed animals $^{(12)}$. However, there is no evidence to support whether or not oligonol has any effect on the regulation of renal lipid metabolism, AGE-induced oxidative stress, and inflammation in the kidney of obesity-induced type 2 diabetes. Therefore, we investigated the effects of oligonol on renal damage induced by hyperglycaemia, and abnormal lipid synthesis and AGE formation were examined in the kidney of $d b / d b$ mice.

\section{Materials and methods}

\section{Oligonol}

Oligonol was generated by oligomerising polyphenol polymers derived from lychee fruit. The safety of oligonol as a food, dietary supplement and pharmaceutical additive has already been confirmed ${ }^{(7)}$. Oligonol comprises a polyphenol mixture of $16.0 \%$ monomers (catechin, epicatechin, epicatechin gallate and epigallocatechin gallate) and $13.9 \%$ dimers (procyanidin A1, A2, B1 and B2), while lychee fruit polyphenol comprises a mixture of $6.4 \%$ monomers and $9.8 \%$ dimers. Oligonol is commercially available (Amino Up Chemical Co., Ltd, Sapporo, Japan).

\section{Materials}

Protease inhibitor mixture solution, 4,6-dihydroxy-2-mercaptopyrimidine (2-thiobarbituric acid), EDTA, reduced glutathione (GSH) and oxidised glutathione (GSSG) were purchased from Wako Pure Chemical Industries, Ltd (Osaka, Japan). 2', $7^{\prime}$ Dichlorofluorescein diacetate was purchased from Molecular Probes (Eugene, OR, USA). The Bio-Rad protein assay kit and pure nitrocellulose membrane were purchased from Bio-Rad Laboratories (Tokyo, Japan). $\beta$-Actin, $o$-phthalaldehyde, phenylmethylsulfonyl fluoride and $N$-ethylmaleimide were purchased from Sigma Chemical Co. (St Louis, MO, USA). Rabbit polyclonal antibodies against NF- $\mathrm{Bp} 65$, sterol regulatory element-binding protein (SREBP)-1, SREBP-2, PPAR $\alpha$ and receptor for AGE (RAGE), and mouse monoclonal antibody against cyclo-oxygenase-2 (COX-2) and inducible NO synthase (iNOS) were purchased from Santa Cruz Biotechnology, Inc. (Santa Cruz, CA, USA). Monoclonal anti- $N^{\varepsilon}$-(carboxyethyl)lysine (CEL) antibody and polyclonal anti- $N^{\varepsilon}$-(carboxymethyl)lysine (CML) antibody were kindly provided by Dr R. Nagai (Kumamoto University, Japan). Goat anti-rabbit and goat anti-mouse IgG horseradish peroxidase-conjugated secondary antibodies were purchased from Santa Cruz Biotechnology, Inc. (Santa Cruz, CA, USA). ECL Western Blotting Detection Reagents were purchased from Amersham Bioscience (Piscataway, NJ, USA).

\section{Experimental animals and treatment}

The 'Guidelines for Animal Experimentation' approved by the University of Toyama were followed in the present study (registration no. S-2006 INM-22). Male C57BLKS/J $d b / d b$ and $\mathrm{m} / \mathrm{m}$ (misty, non-diabetic) mice, aged 5 weeks, were purchased from Japan SLC Inc. (Hamamatsu, Japan), and housed with free access to laboratory pellet chow (CLEA Japan Inc., Tokyo, Japan), comprising $60.5 \%$ carbohydrates, $24.0 \%$ proteins and $3.5 \%$ lipids, and water. They were maintained in a controlled environment $\left(22 \pm 2^{\circ} \mathrm{C}, 50 \pm 5 \%\right.$ humidity, $12 \mathrm{~h}$ light $-12 \mathrm{~h}$ dark cycle). After adaptation, glucose levels of blood taken from the tail vein and the body weight were measured, and then $d b / d b$ mice were divided into three groups. The $d b / d b$ vehicle group ( $n 10)$ was orally administered water, while the other two groups (n 10 per group) were orally administered oligonol every day at a dose of 10 or $20 \mathrm{mg} / \mathrm{kg}$ body weight, respectively. The nondiabetic $\mathrm{m} / \mathrm{m}$ mice $(n 6)$ as a normal group were compared with the diabetic groups. Food and water intakes were determined every day during the experimental period. After administration for 8 weeks, blood samples were collected by the cardiac puncture of anaesthetised mice. Serum was separated immediately after centrifugation. Subsequently, each mouse was perfused with ice-cold physiological saline, and then the kidneys were harvested, snap-frozen in liquid $\mathrm{N}_{2}$ and stored at $-80^{\circ} \mathrm{C}$ until analysis.

\section{Assay of serum samples}

Serum glucose, TAG, total cholesterol and NEFA were measured using commercial kits (Glucose CII-Test, Triglyceride E-Test, Cholesterol E-Test and NEFA C-Test, respectively, from WAKO Pure Chemical Industries, Ltd, Osaka, Japan). For the measurement of serum urea $\mathrm{N}$ and creatinine, BUN Kainos and CRE-EN Kainos were obtained from Kainos Laboratory Inc. (Tokyo, Japan). Serum insulin and leptin (Morinaga Institute of Biological Science, Yokohama, Japan), adiponectin (CycLex Co., Ltd, Nagano, Japan) and hexanoyl-lysine (Institute for the Control of Aging, Shizuoka, Japan) levels were measured based on ELISA. The serum reactive oxygen species (ROS) level was determined using the method of Ali et al. ${ }^{(13)}$, and the 2-thiobarbituric acidreactive substance (TBARS) level was examined by employing the method of Naito \& Yamanaka ${ }^{(14)}$.

Determination of glucose, TAG and total cholesterol contents in the kidney

To measure the glucose concentration in the kidney, tissue was homogenised with $0.9 \% \mathrm{NaCl}, 0.15 \mathrm{M}-\mathrm{Ba}(\mathrm{OH})_{2}$ and $5 \%$ $\mathrm{ZnSO}_{4}$ were added, and then it was centrifuged at $1400 \mathrm{~g}$ for $15 \mathrm{~min}$ at $4^{\circ} \mathrm{C}^{(15)}$. The glucose concentration of the supernatant fraction was evaluated using a Wako kit (Glucose CII-Test). Total lipids were extracted with a mixture of chloroform and methanol $(2: 1, \mathrm{v} / \mathrm{v})$ according to the method of Folch et al. ${ }^{(16)}$, and TAG and total cholesterol levels were measured using the Wako kits, as described above.

\section{Assay of reactive oxygen species and 2-thiobarbituric acid-reactive substance levels in the kidney}

ROS generation was measured by employing the method of Ali et $a l .{ }^{(13)}$. Renal tissue was homogenised on ice with $1 \mathrm{~mm}$-EDTA-50 mM-sodium phosphate buffer ( $\mathrm{pH} 7 \cdot 4$ ). In brief, $25 \mathrm{~mm}-2^{\prime}, 7^{\prime}$-dichlorofluorescein diacetate was added 
to homogenates, and, after $30 \mathrm{~min}$, changes in fluorescence were determined at an excitation wavelength of $486 \mathrm{~nm}$ and emission wavelength of $530 \mathrm{~nm}$. TBARS levels were estimated according to the method of Mihara \& Uchiyama ${ }^{(17)}$.

\section{Determination of reduced and oxidised glutathione levels in the kidney}

GSH and GSSG assays were carried out using the method of Hissin \& Hilf ${ }^{(18)}$. Renal tissue was homogenised on ice with $1 \mathrm{mM}-\mathrm{EDTA}-100 \mathrm{~mm}$-sodium phosphate buffer (pH 8.0). Then, $25 \%$ meta-phosphoric acid was added to precipitate protein. The homogenate was centrifuged at $4^{\circ} \mathrm{C}$ at $100000 \mathrm{~g}$ for $30 \mathrm{~min}$. The supernatant fraction was used for assays of GSH and GSSG. To assay for GSH, the supernatant fraction was diluted with buffer followed by $o$-phthalaldehyde. For the determination of the GSSG concentration, after preincubation with $\mathrm{N}$-ethylmaleimide for $20 \mathrm{~min}, 0 \cdot 1 \mathrm{M}-\mathrm{NaOH}$ was used instead of sodium phosphate buffer $(\mathrm{pH}$ 8.0). After $15 \mathrm{~min}$ at room temperature, fluorescence was estimated at an excitation wavelength of $360 \mathrm{~nm}$ and emission wavelength of $460 \mathrm{~nm}$. The protein concentration was measured according to the method of Itzhaki \& Gill $^{(19)}$ using bovine serum albumin as a standard.

\section{Preparation of nuclear and post-nuclear fractions}

To prepare nuclear fractions, the kidney was homogenised with ice-cold lysis buffer containing $5 \mathrm{~mm}$-2-amino-2-hydroxymethyl-propane-1,3-diol (Tris)- $\mathrm{HCl}$ ( $\mathrm{pH} 7 \cdot 5$ ), 2 mM- $\mathrm{MgCl}_{2}$, $15 \mathrm{~mm}-\mathrm{CaCl}_{2}$ and $1.5 \mathrm{M}$-sucrose, and then $0.1 \mathrm{M}$-dithiothreitol (DTT) and protease inhibitor cocktail were added. After samples were centrifuged at $10500 \mathrm{~g}$ for $20 \mathrm{~min}$ at $4^{\circ} \mathrm{C}$, the pellet was suspended with nuclear extraction buffer (20 mM-2[4-(2-hydroxyethyl)-1-piperazinyl]ethanesulfonic acid ( $\mathrm{pH} 7.9), 1.5 \mathrm{~mm}-$ $\mathrm{MgCl}_{2}, 0.42 \mathrm{M}-\mathrm{NaCl}, 0.2 \mathrm{~mm}-\mathrm{EDTA}, 25 \%$ (v/v) glycerol, $0 \cdot 1 \mathrm{M}$-DTT and protease inhibitor cocktail). After the mixture was placed on ice for $30 \mathrm{~min}$, the nuclear fraction was prepared by centrifugation at $20500 \mathrm{~g}$ for $5 \mathrm{~min}$ at $4^{\circ} \mathrm{C}$. The post-nuclear fraction was extracted from the kidney of each mouse, as described below. In brief, renal tissue was homogenised with ice-cold lysis buffer ( $\mathrm{pH} 7 \cdot 4$ ) containing $137 \mathrm{mM}-\mathrm{NaCl}$, $20 \mathrm{~mm}$-2-amino-2-hydroxymethyl-propane-1,3-diol (Tris)$\mathrm{HCl}, 1 \%$ Tween 20, $10 \%$ glycerol, 1 mM-phenylmethylsulfonyl fluoride and protease inhibitor mixture. The homogenate was then centrifuged at $2000 \mathrm{~g}$ for $10 \mathrm{~min}$ at $4^{\circ} \mathrm{C}$. The protein concentration of each fraction was determined using the Bio-Rad protein kit with bovine serum albumin as a standard.

\section{Western blot analysis}

Post-nuclear protein $(40 \mu \mathrm{g})$ for RAGE, CEL, CML, COX-2 and iNOS expression and nuclear protein $(40 \mu \mathrm{g})$ for PPAR $\alpha$, SREBP-1, SREBP-2 and NF-кBp65 were electrophoresed in $8-10 \%$ SDS-polyacrylamide gel. Separated proteins were transferred to a pure nitrocellulose membrane, blocked with $5 \%$ skimmed milk solution for $1 \mathrm{~h}$, and then incubated with primary antibodies overnight at $4^{\circ} \mathrm{C}$. After washing of the membrane, it was incubated with goat anti-rabbit or goat anti-mouse IgG horseradish peroxidaseconjugated secondary antibody for $1 \mathrm{~h}$ at room temperature.
Each antigen-antibody complex was visualised using ECL Western Blotting Detection Reagents and detected by chemiluminescence with LAS-4000 (Fujifilm, Tokyo, Japan). Band densities were calculated by employing an image analyser ATTO densitograph (ATTO, Tokyo, Japan) and normalised to $\beta$-actin. The protein expression levels are presented relative to those of $\mathrm{m} / \mathrm{m}$ mice (represented as 1).

\section{Statistical analysis}

All results are expressed as mean values with their standard errors, and analysed statistically using one-way ANOVA followed by Dunnett's test for individual differences among groups. Values of $P<0.05$ were considered significant.

\section{Results}

Food and water intake, and body-weight gain

The food and water intakes as well as body-weight gain of the $d b / d b$ mice after 8 weeks were significantly higher than those of the age-matched $\mathrm{m} / \mathrm{m}$ mice. There were no changes in food and water intake or body-weight gain among the $d b / d b$ mouse groups (data not shown).

\section{Haematological analysis}

Table 1 shows the serum constituents (glucose, TAG, total cholesterol and NEFA), glucose and lipid metabolism-related hormones (insulin, leptin and adiponectin), renal functional parameters (urea $\mathrm{N}$ and creatinine) and biomarkers associated with oxidative stress (ROS, hexanoyl-lysine and TBARS). Except for serum adiponectin, all serum constituents and biomarkers were elevated in $d b / d b$ vehicle compared with $\mathrm{m} / \mathrm{m}$ mice. Treatment with oligonol did not alter the serum glucose and leptin concentrations; however, it significantly increased the insulin level. The $d b / d b$ mice administered oligonol at $20 \mathrm{mg} / \mathrm{kg}$ showed significant reductions in the levels of TAG, total cholesterol, NEFA, ROS, hexanoyllysine, TBARS, urea $\mathrm{N}$ and creatinine. The serum adiponectin level was significantly lower in the $d b / d b$ vehicle than in the $\mathrm{m} / \mathrm{m}$ mice, while oligonol administration elevated its reduced concentration. Also, the levels of urea $\mathrm{N}$ and creatinine were significantly increased in $d b / d b$ vehicle compared with $\mathrm{m} / \mathrm{m}$ mice. However, these increased levels were markedly decreased by treatment with oligonol at $20 \mathrm{mg} / \mathrm{kg}$.

\section{Biomarkers associated with oxidative stress in the kidney}

In $d b / d b$ vehicle mice, the ROS concentration in the kidney was markedly increased compared with that in $\mathrm{m} / \mathrm{m}$ mice, but the 10 or $20 \mathrm{mg}$ oligonol treatment reduced this increase to 36 or $75 \%$, respectively (Table 2). Also, renal TBARS levels were increased by 1.36 times compared with $\mathrm{m} / \mathrm{m}$ mice $(\mathrm{m} / \mathrm{m}, 1.11 ; \mathrm{db} / \mathrm{db}$ mice, $1.51 \mathrm{nmol} / \mathrm{mg}$ protein; $P<0 \cdot 01)$. However, the elevated renal TBARS levels were significantly reduced in the oligonol-treated $d b / d b$ mouse groups, and were lowered nearly to the levels of the $\mathrm{m} / \mathrm{m}$ mice by treatment with oligonol at $20 \mathrm{mg} / \mathrm{kg}$. Regarding GSH:GSSG ratios, the $d b / d b$ vehicle group showed a significant reduction compared with the $\mathrm{m} / \mathrm{m}$ group, which resulted 
Table 1. Haematological analyses

(Mean values with their standard errors)

\begin{tabular}{|c|c|c|c|c|c|c|c|c|}
\hline & & & \multicolumn{6}{|c|}{$d b / d b$} \\
\hline & \multicolumn{2}{|c|}{$\mathrm{m} / \mathrm{m}$} & \multicolumn{2}{|c|}{ Vehicle } & \multicolumn{2}{|c|}{ Oligo-10 } & \multicolumn{2}{|c|}{ Oligo-20 } \\
\hline & Mean & SE & Mean & SE & Mean & SE & Mean & SE \\
\hline Glucose (mg/l) & $1529^{\star \star \star}$ & 122 & 5940 & 293 & 5712 & 611 & 6684 & 409 \\
\hline Insulin (ng/ml) & $0 \cdot 17^{\star \star *}$ & 0.08 & 1.77 & 0.18 & 1.71 & 0.22 & $2 \cdot 86^{\star \star}$ & 0.32 \\
\hline Leptin (ng/ml) & $3 \cdot 00^{\star \star \star}$ & 0.39 & 19.80 & 0.32 & 19.45 & 0.22 & $19 \cdot 28$ & 0.35 \\
\hline TAG (mg/l) & $752^{\star \star \star}$ & 60 & 2198 & 181 & 1970 & 300 & $1608^{*}$ & 202 \\
\hline Total cholesterol (mg/l) & $760^{\star \star \star}$ & 37 & 1568 & 126 & 1387 & 82 & $1242^{*}$ & 65 \\
\hline Adiponectin $(\mathrm{ng} / \mathrm{ml})$ & $6 \cdot 12^{\star \star \star}$ & 0.62 & 2.42 & 0.23 & $2.93^{\star}$ & 0.20 & $3 \cdot 12^{*}$ & 0.12 \\
\hline NEFA $(\mathrm{mEq} / \mathrm{l})$ & $0.74^{\star \star *}$ & 0.10 & 1.41 & 0.08 & $1 \cdot 18$ & 0.13 & $1 \cdot 10^{*}$ & 0.09 \\
\hline ROS (fluorescence/min per ml) & $170 \cdot 7^{\star}$ & $27 \cdot 0$ & 321.0 & $42 \cdot 3$ & $213 \cdot 8^{*}$ & $24 \cdot 2$ & $144 \cdot 8^{* *}$ & 23.5 \\
\hline Hexanoyl-lysine (nmol/l) & 0.19 & 0.06 & 0.49 & 0.18 & $0 \cdot 12^{*}$ & 0.02 & 0.21 & 0.02 \\
\hline TBARS (nmol MDA/ml) & $5 \cdot 70^{\star \star \star}$ & 0.15 & 14.93 & 1.33 & $13 \cdot 35$ & $1 \cdot 14$ & $7 \cdot 09^{\star \star \star}$ & 0.29 \\
\hline Urea N (mg/l) & $315 \cdot 0^{\star \star}$ & 29.0 & 443.6 & 24.2 & 404.0 & 24.4 & $286 \cdot 4^{\star \star \star}$ & $17 \cdot 2$ \\
\hline Creatinine $(\mathrm{mg} / \mathrm{l})$ & $2 \cdot 3^{*}$ & 0.2 & 3.5 & 0.4 & 3.7 & 0.4 & $2 \cdot 6^{*}$ & 0.2 \\
\hline
\end{tabular}

$\mathrm{m} / \mathrm{m}$, non-diabetic misty mice; Vehicle, $d b / d b$ vehicle-treated mice; Oligo-10, $d b / d b$ mice treated with oligonol at $10 \mathrm{mg} / \mathrm{kg}$ body weight; Oligo-20, $d b / d b$ mice treated with oligonol at $20 \mathrm{mg} / \mathrm{kg}$ body weight; ROS, reactive oxygen species; TBARS, thiobarbituric acid-reactive substances; MDA, malondialdehyde.

Mean value was significantly different from that of the vehicle group: ${ }^{\star} P<0.05,{ }^{\star \star} P<0.01,{ }^{\star \star \star} P<0.001$

from the marked increase in the GSSG concentration in the kidney. However, oligonol treatment did not significantly alter the renal GSH level and GSH:GSSG ratio (Table 2).

\section{Kidney weight and renal glucose, TAG and total cholesterol levels}

The kidney weights in the three groups of $d b / d b$ mice were greater than that of the $\mathrm{m} / \mathrm{m}$ mice (Table 3). The glucose level in the kidney of the $d b / d b$ vehicle mice showed a more than 2.58-fold increase compared with that of the $\mathrm{m} / \mathrm{m}$ mice. Also, there was a 1.49-fold increase in the TAG content and a 1.56-fold increase in the cholesterol content of the kidney of the $d b / d b$ vehicle mice compared with those of the $\mathrm{m} / \mathrm{m}$ mice. However, these increments in renal TAG and cholesterol levels were significantly reduced by 10 or $20 \mathrm{mg}$ oligonol administration, as shown in Table 3.

\section{Protein expression related to lipid metabolism in the kidney}

Renal PPAR $\alpha$ protein expression decreased in $d b / d b$ vehicle compared with $\mathrm{m} / \mathrm{m}$ mice; however, the group treated with oligonol at $20 \mathrm{mg} / \mathrm{kg}$ showed an up-regulation of PPAR $\alpha$ protein expression (Fig. 1). The protein expressions of renal SREBP-1 and SREBP-2 in $d b / d b$ mice were significantly higher than those of $\mathrm{m} / \mathrm{m}$ mice, respectively. The $d b / d b$ mice administered oligonol at $20 \mathrm{mg} / \mathrm{kg}$, however, showed significantly reduced protein expressions of SREBP-1 but not SREBP-2 compared with $d b / d b$ vehicle mice (Fig. 1).

\section{Protein expressions of receptor for advanced glycation endproducts, $\mathrm{N}^{\varepsilon}$-(carboxyethyl)lysine and $\mathrm{N}^{\varepsilon}$-(carboxymethyl)lysine in the kidney}

To evaluate RAGE, CEL and CML protein expressions in the kidney, we performed Western blot analyses. As shown in Fig. 2, renal RAGE, CEL and CML were elevated in $d b / d b$ vehicle compared with $\mathrm{m} / \mathrm{m}$ mice $(2.34,2.69$ and 4.36-fold, respectively). However, the oligonol-treated group showed a significant down-regulation of these AGE and their receptors.

\section{Expression of inflammatory proteins in the kidney}

In the $d b / d b$ vehicle group, NF-кBp65, COX-2 and iNOS protein expressions were significantly up-regulated compared

Table 2. Biomarkers associated with oxidative stress in the kidney

(Mean values with their standard errors)

\begin{tabular}{|c|c|c|c|c|c|c|c|c|}
\hline & & & \multicolumn{6}{|c|}{$d b / d b$} \\
\hline & \multicolumn{2}{|c|}{$\mathrm{m} / \mathrm{m}$} & \multicolumn{2}{|c|}{ Vehicle } & \multicolumn{2}{|c|}{ Oligo-10 } & \multicolumn{2}{|c|}{ Oligo-20 } \\
\hline & Mean & SE & Mean & SE & Mean & SE & Mean & SE \\
\hline ROS (fluorescence/min per mg protein) & $1056 \cdot 6^{\star \star}$ & 93.9 & $3069 \cdot 2$ & $327 \cdot 3$ & $1969 \cdot 7^{\star}$ & $282 \cdot 2$ & $763 \cdot 9^{\star \star \star}$ & $111 \cdot 8$ \\
\hline TBARS (nmol MDA/mg protein) & $1 \cdot 11^{\star \star}$ & 0.05 & 1.51 & 0.07 & 1.37 & 0.05 & $1 \cdot 18^{*}$ & 0.09 \\
\hline GSH ( $\mu \mathrm{mol} / \mathrm{mg}$ protein) & 3.02 & $0 \cdot 18$ & 2.95 & 0.09 & $3 \cdot 23$ & 0.33 & 3.08 & $0 \cdot 17$ \\
\hline GSSG ( $\mu \mathrm{mol} / \mathrm{mg}$ protein) & $1.40^{* *}$ & 0.03 & 1.63 & 0.04 & $1 \cdot 47^{\star}$ & 0.05 & 1.52 & 0.06 \\
\hline GSH:GSSG ratio & $2 \cdot 17^{\star}$ & 0.13 & 1.80 & 0.04 & $2 \cdot 19$ & 0.18 & 2.05 & 0.15 \\
\hline
\end{tabular}

$\mathrm{m} / \mathrm{m}$, non-diabetic misty mice; Vehicle, $d b / d b$ vehicle-treated mice; Oligo-10, $d b / d b$ mice treated with oligonol at $10 \mathrm{mg} / \mathrm{kg}$ body weight; Oligo-20, $d b / d b$ mice treated with oligonol at $20 \mathrm{mg} / \mathrm{kg}$ body weight; ROS, reactive oxygen species; TBARS, thiobarbituric acid-reactive substances; MDA, malondialdehyde; GSH, reduced glutathione; GSSG, oxidised glutathione.

Mean value was significantly different from that of the vehicle group: ${ }^{\star} P<0.05,{ }^{\star \star} P<0.01,{ }^{\star \star \star} P<0.001$. 
Table 3. Kidney weight and renal glucose, TAG and total cholesterol contents (Mean values with their standard errors)

\begin{tabular}{|c|c|c|c|c|c|c|c|c|}
\hline & & & \multicolumn{6}{|c|}{$d b / d b$} \\
\hline & \multicolumn{2}{|c|}{$\mathrm{m} / \mathrm{m}$} & \multicolumn{2}{|c|}{ Vehicle } & \multicolumn{2}{|c|}{ Oligo-10 } & \multicolumn{2}{|c|}{ Oligo-20 } \\
\hline & Mean & SE & Mean & SE & Mean & SE & Mean & SE \\
\hline Kidney weight (g) & $0.32^{\star \star \star}$ & 0.01 & 0.43 & 0.01 & 0.45 & 0.02 & 0.46 & 0.01 \\
\hline Glucose (mg/g tissue) & $0.95^{\star \star *}$ & 0.07 & 2.45 & 0.23 & 2.06 & 0.20 & 1.92 & 0.12 \\
\hline TAG (mg/g tissue) & $3 \cdot 01^{\star \star}$ & 0.19 & 4.48 & 0.19 & $3 \cdot 25^{\star}$ & 0.24 & $2 \cdot 96^{\star \star \star}$ & 0.11 \\
\hline Total cholesterol (mg/g tissue) & $1 \cdot 71^{*}$ & 0.20 & $2 \cdot 66$ & 0.23 & $1 \cdot 89^{\star}$ & 0.05 & $2.09^{*}$ & 0.08 \\
\hline
\end{tabular}

with those of the $\mathrm{m} / \mathrm{m}$ group (Fig. 3). These increased expressions of proteins related to inflammation and ROS generation in the kidney were markedly reduced by the administration of oligonol, which means the deactivation of $\mathrm{NF}-\kappa \mathrm{B}$ and down-regulation of NF-кB related to COX-2 and iNOS.

\section{Discussion}

Oligonol is a phenolic product derived from lychee fruit extract containing catechin-type monomers and oligomers of proanthocyanidins, produced by a manufacturing process which converts polyphenol polymers into oligomers ${ }^{(20)}$. Oligonol is produced by the oligomerisation of polyphenol polymers, typically proanthocyanidins; thus, oligonol delivers higher levels of oligomeric proanthocyanidins compared with fruit and plant sources that generally contain high-molecularweight proanthocyanidins. Oligonol reflects the phenolic composition of lychee fruit and includes monomers of catechin, epicatechin, epicatechin gallate and epigallocatechin gallate, and oligomers of procyanidin $\mathrm{A} 1$, procyanidin $\mathrm{A} 2$, procyanidin $\mathrm{B} 1$ and procyanidin $\mathrm{B} 2^{(21)}$. These proanthocyanidins have been reported to exhibit beneficial bioactivities in many studies, and so oligonol, a rich source of polyphenol, has been expected to show favourable effects on various chronic diseases. Of course, many beneficial physiological activities of oligonol on antioxidants, anticancer, anti-ageing and anti-inflammation, have been reported, while, in type 2 diabetes, the effects of oligonol on the kidney have not yet been determined. Therefore, we investigated the protective effects of oligonol against renal lipid metabolism, oxidative stress, AGE formation and inflammation in C57BLKS/J $d b / d b$ mice.

In the present study, the effects of oligonol on serum parameters such as glucose and lipid levels as well as their related hormones were examined. We found that $d b / d b$ mice showed hyperglycaemia as well as hyperlipidaemia. The administration of oligonol reduced hyperlipidaemia through lowering TAG, total cholesterol and NEFA. However, oligonol treatment did not affect the serum glucose concentration in spite of elevated serum insulin (Table 1). In oligonol-administered $d b / d b$ mice, the cause of increased insulin secretion is unclear and may be related to the preservation of pancreatic $\beta$-cell function by oligonol treatment. In the study of Kanda et al., $d b / d b$ mice exhibited the apoptosis of pancreatic $\beta$-cells which were readily detectable at 8 weeks of age, and decreased cell proliferation at 12 weeks of age with a reduced insulin content in pancreatic islets ${ }^{(22)}$. Additionally, serum adiponectin concentrations were significantly higher in the (a)

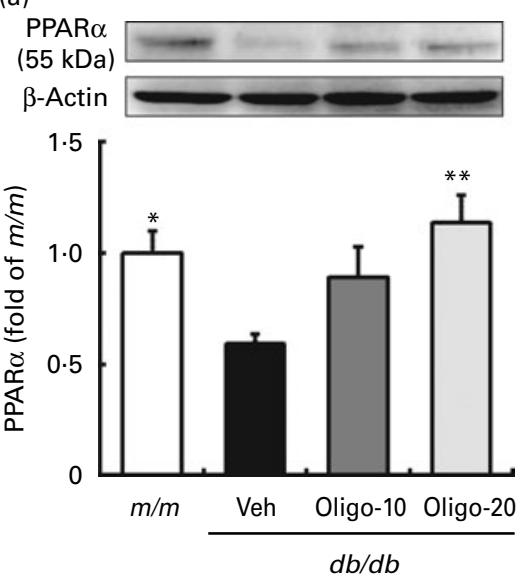

(b)

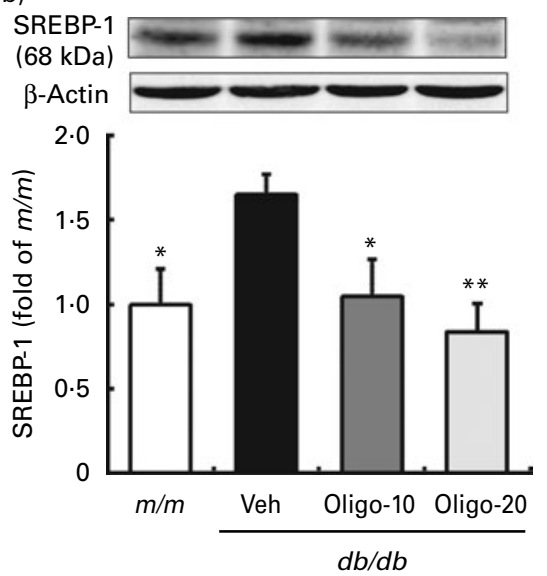

(c)

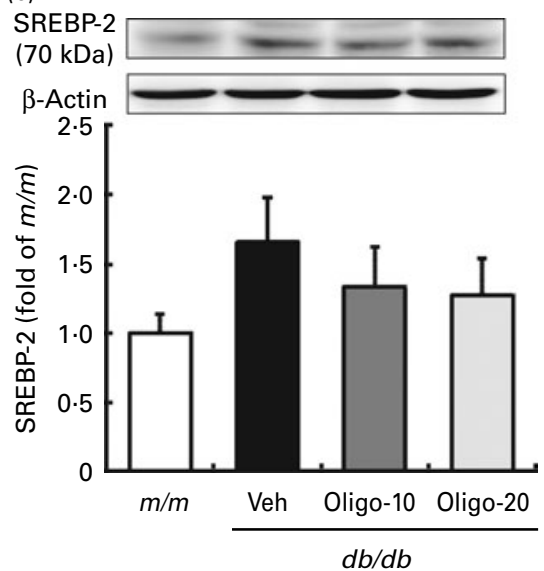

Fig. 1. PPAR $\alpha$ (a), sterol regulatory element-binding protein (SREBP)-1 (b) and SREBP-2 (c) expressions in renal tissues. $m / m$, Non-diabetic misty mice; Veh, $d b / d b$ vehicle-treated mice; Oligo-10, $d b / d b$ mice treated with oligonol at $10 \mathrm{mg} / \mathrm{kg}$ body weight; Oligo- $20, d b / d b$ mice treated with oligonol at $20 \mathrm{mg} / \mathrm{kg}$ body weight. Values are means, with standard errors represented by vertical bars. Mean value was significantly different from that of the vehicle group: ${ }^{*} P<0.05,{ }^{*} P<0.01$. 
(a)

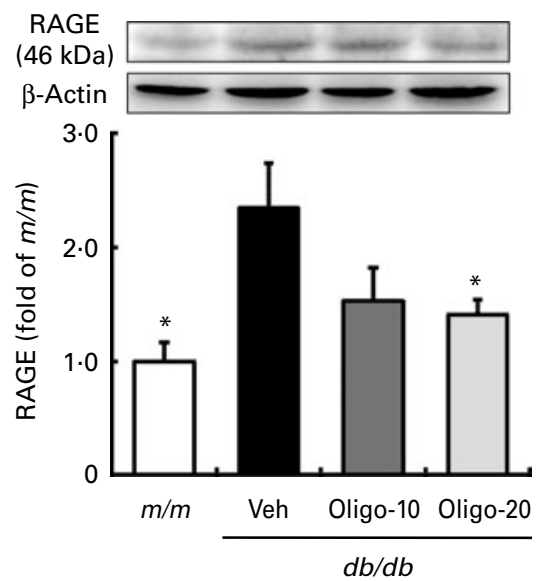

(b)

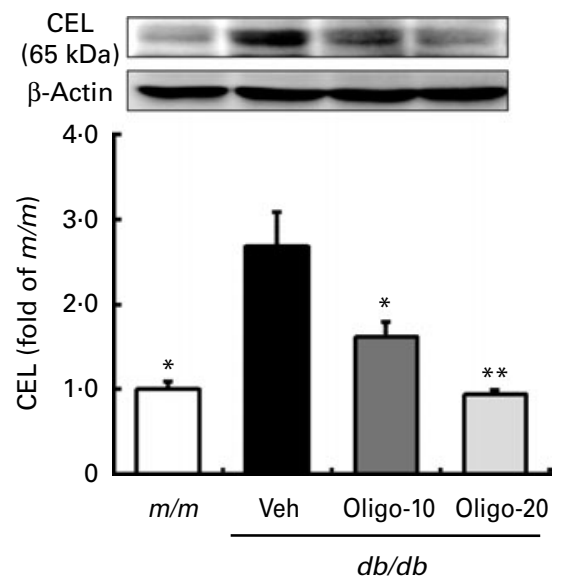

(c)

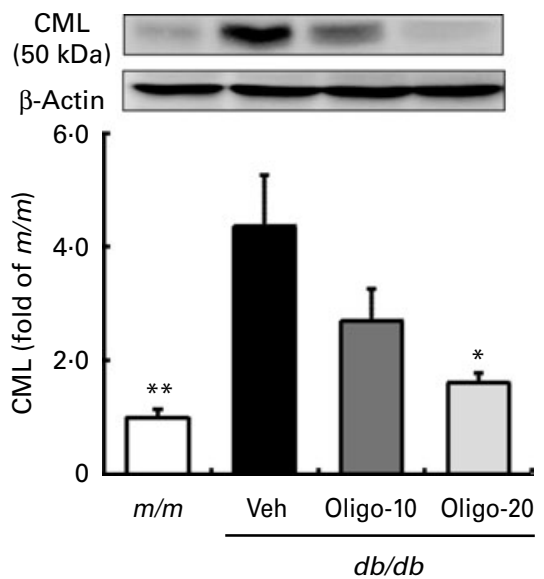

Fig. 2. Receptor for advanced glycation endproducts (RAGE) (a), $N^{\varepsilon}$-(carboxyethyl)lysine (CEL) (b) and $N^{\varepsilon}$-(carboxymethyl)lysine (CML) (c) expressions in renal tissues. $\mathrm{m} / \mathrm{m}$, Non-diabetic misty mice; Veh, $d b / d b$ vehicle-treated mice; Oligo-10, $d b / d b$ mice treated with oligonol at $10 \mathrm{mg} / \mathrm{kg}$ body weight; Oligo-20, $d b / d b$ mice treated with oligonol at $20 \mathrm{mg} / \mathrm{kg}$ body weight. Values are means, with standard errors represented by vertical bars. Mean value was significantly different from that of the vehicle group: ${ }^{\star} P<0.05,{ }^{\star *} P<0.01$.

oligonol-treated than in the vehicle $d b / d b$ group. Low adiponectin levels are associated with insulin resistance in type 2 diabetic patients and experimental animals ${ }^{(23)}$. Unfortunately, we cannot measure the insulin sensitivity regarding the influence on target tissues such as muscle and fat. However, other than serum glucose and insulin levels, through oligonol administration, other biofactors such as the lipid profile and oxidative stress were favourable under type 2 diabetic conditions, especially kidney damage. In addition, to investigate the effects of oligonol on renal damage induced by hyperglycaemia and abnormal lipid synthesis, the levels of hyperglycaemia and hyperlipidaemia in the kidneys of $d b / d b$ mice were also examined. The renal contents of TAG and total cholesterol were significantly decreased by the administration of oligonol (Table 3). These results indicate that the biological activities of oligonol in the serum of $d b / d b$ mice are associated with lipid metabolism such as synthesis or deposition for energy production.
Hyperglycaemia and elevated NEFA levels result in the generation of ROS, and, consequently, increase oxidative stress. ROS not only directly damage cells by oxidising DNA, proteins and lipids, but also indirectly damage them by activating a variety of stress-sensitive intracellular signalling pathways such as NF-кB, p38 mitogen-activated protein kinase (MAPK), $\mathrm{NH}_{2}$-terminal Jun kinase/stress-activated protein kinase, hexosamines, protein kinase $\mathrm{C}$, AGE/RAGE and others. Activation of these pathways results in the increased expression of numerous gene products that cause cellular damage and play a major role in the aetiology of the later-stage complications of diabetes ${ }^{(24)}$. Thus, the up-regulation of endogenous antioxidative systems and suppression of oxidative stress are important factors ameliorating diabetes and its complications. In the present study, we investigated ROS generation and lipid peroxidation, as biomarkers associated with oxidative stress, and also measured GSH and GSSG as indicators of an endogenous (a)

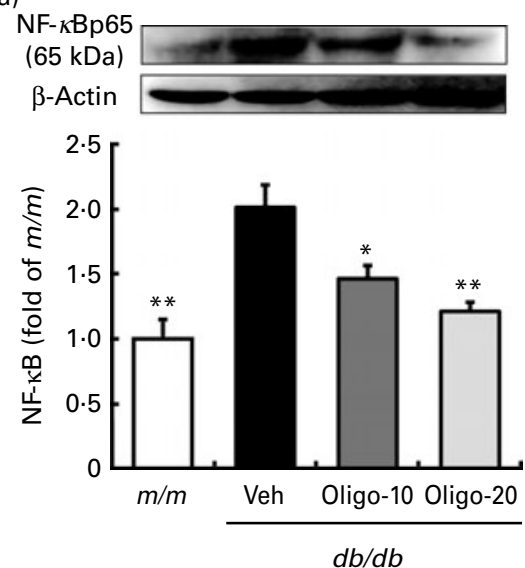

(b)
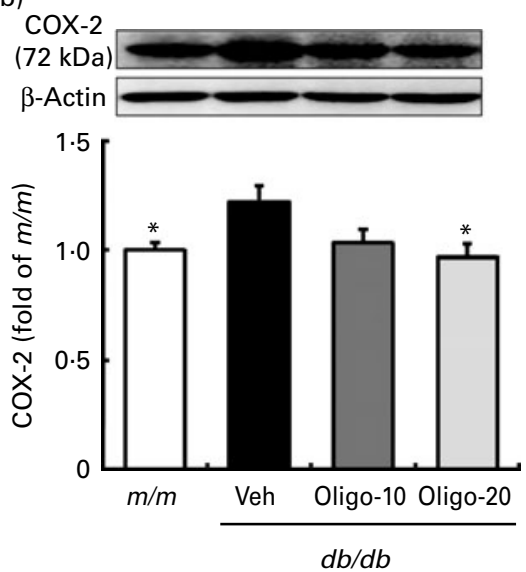

(c)
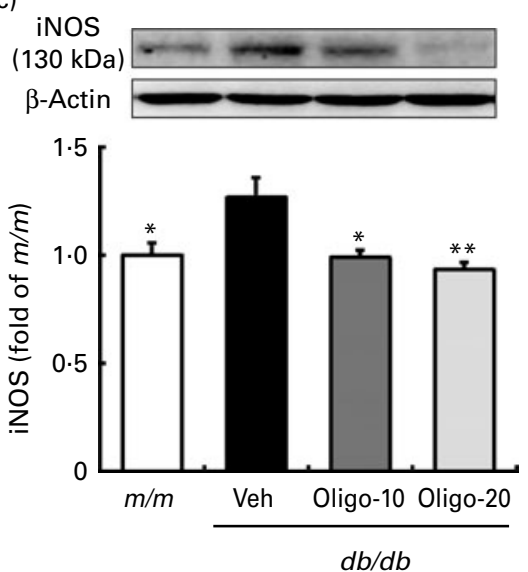

Fig. 3. NF-кBp65 (a), cyclo-oxygenase-2 (COX-2) (b) and inducible NO synthase (iNOS) (c) expressions in renal tissues. $m / m$, Non-diabetic misty mice; Veh, $d b / d b$ vehicle-treated mice; Oligo-10, $d b / d b$ mice treated with oligonol at $10 \mathrm{mg} / \mathrm{kg}$ body weight; Oligo-20, $d b / d b$ mice treated with oligonol at $20 \mathrm{mg} / \mathrm{kg}$ body weight. Values are means, with standard errors represented by vertical bars. Mean value was significantly different from that of the vehicle group: ${ }^{\star} P<0.05$, ${ }^{\star \star} P<0.01$. 
antioxidative system. Lipid peroxidation also leads to oxidant production from many molecules, and, thus, amplifies oxidative damage ${ }^{(25)}$. The present results showed that the level of ROS generation and that of lipid peroxidation in the serum and kidney were increased in $d b / d b$ mice, which implies that these mice show increased oxidative damage due to an elevation of ROS generation induced by hyperglycaemia and hyperlipidaemia. However, oligonol treatment exerted antioxidant activity, promoting decreased serum ROS and TBARS levels with corresponding effects on renal tissue in $d b / d b$ mice (Table 2). This suggests that the administration of oligonol would ameliorate oxidative stress under type 2 diabetes through the inhibition of ROS generation and lipid peroxidation, and, thus, it would result in the improvement of renal disorders caused by oxidative stress.

Lipid homeostasis is regulated by a family of membranebound transcription factors called SREBP. Up-regulations of SREBP-1 and SREBP-2 were reported in leptin-resistant mice such as $o b / o b$ and $\mathrm{FVB}^{d b / d b}$ mice $^{(26,27)}$. In the present study, the increase in renal SREBP-1 and SREBP-2 in $d b / d b$ mice was down-regulated by the administration of oligonol. This was probably related to the inhibition of renal TAG and total cholesterol accumulation. Furthermore, PPAR, with three isoforms $(\alpha, \delta$ and $\gamma$ ), are also involved in the long-term regulation of lipid metabolism, and their activity is modulated by endogenous lipid-derived ligands. When PPAR $\alpha$ is activated, it promotes fatty acid oxidation, ketone body synthesis and glucose sparing ${ }^{(28)}$ and ameliorates diabetes, insulin resistance, albuminuria, glomerular hypertrophy and mesangial expansion in $d b / d b$ mice $^{(29)}$. In the present study, the decreased renal PPAR $\alpha$ level in $d b / d b$ mice was significantly increased on oligonol administration. These results clarify the effect of oligonol on regulations of both PPAR $\alpha$ and SREBP.

AGE are complex compounds formed via a non-enzymic reaction between reducing sugars and amine residues on proteins, lipids or nucleic acids ${ }^{(4)}$. The intracellular production and accumulation of AGE are closely linked to diabetic complications such as neuropathy, retinopathy and nephropathy ${ }^{(3,30)}$. Especially, there is a strong correlation between AGE accumulation and the duration and degree of severity of diabetic kidney disease ${ }^{(5)}$. AGE can interact with certain receptors, such as RAGE, to induce intracellular signalling, which leads to enhanced oxidative stress and the production of key pro-inflammatory and prosclerotic cytokines. Recently, attention has been focused on the essential roles of AGE, that is, AGE alter the structure and function of matrix tissue proteins, and AGE-modified proteins stimulate a variety of cellular responses via a specific cell surface receptor, resulting in the expression and activation of pathogenic mediators, for example, the extracellular matrix, oxidative stress, cytokines and growth factors implicated in the development and stimulation of diabetic renal diseases ${ }^{(31)}$. In the present study, we performed Western blot analyses of kidney tissue, evaluating AGE actions with receptors related to intracellular responses and the renal AGE level characterised physico-chemically by neither cross-linking nor fluorescence, for example, CEL and CML, identified in ageing and diabetes-related diseases. These products are not only derived from intermediates of glucose metabolism and metabolites of glycolysis, but also serve as general biomarkers of oxidative stress resulting from carbohydrate and lipid oxidation reactions ${ }^{(32)}$. CML formation also takes place through glyoxal, which is generated through the auto-oxidation of glucose ${ }^{(33)}$, oxidative cleavage of Schiff bases ${ }^{(34)}$ and unsaturated fatty acids ${ }^{(35)}$. An enhanced oxidative stress status could lead to CML formation, although CML is generally regarded as a glycoxidation product. CML can also be formed through lipid peroxidation and the generation of glycolaldehyde via the myeloperoxidase pathway ${ }^{(35)}$. Indeed, CML cannot be formed without oxidative stress ${ }^{(30)}$. Therefore, CML could serve as a general biomarker of oxidative stress resulting from carbohydrate and lipid oxidation reactions. Moreover, recent studies have demonstrated that methylglyoxal is generated through the Embden-Meyerhof and polyol pathways, and rapidly reacts with proteins to form methylglyoxal-derived AGE such as $\mathrm{CEL}^{(32)}$. CEL is detected in human lens proteins at a concentration similar to that of CML, and its accumulation increases with age in parallel with that of $\mathrm{CML}^{(36)}$. Consequently, the down-regulation of RAGE, CEL and CML expression is important to improve diabetic kidney disease. In the present study, oligonol markedly reduced renal protein levels of RAGE, CEL and CML in the kidney of $d b / d b$ mice, suggesting that oligonol, with antioxidant activities, has a protective effect against diabetic renal damage caused by RAGE-AGE interactions and complicated complexes of functional protein with CML or CEL.

NF- $\kappa \mathrm{B}$ can be activated by a wide array of exogenous and endogenous stimuli including hyperglycaemia, elevated NEFA, ROS, TNF- $\alpha$, IL-1 $\beta$, other pro-inflammatory cytokines, AGE-binding RAGE and p38 mitogen-activated protein kinase (MAPK). In particular, AGE trigger the activation of $\mathrm{NF}-\kappa \mathrm{B}$ via interaction with RAGE, leading to its translocation to the nucleus where it induces transcription, and the promoter region of the RAGE gene contains NF- $\kappa$ B-binding sites, potentially creating a self-perpetuating pathway ${ }^{(37)}$. The aberrant regulation of NF- $\mathrm{NB}$ is associated with a number of chronic diseases including diabetes and atherosclerosis ${ }^{(36)}$. $\mathrm{NF}-\kappa \mathrm{B}$ regulates the expression of a large number of genes, including growth factors, pro-inflammatory cytokines and others ${ }^{(38,39)}$. NF-кB is involved in the regulation of COX-2 and iNOS expressions that mediate the inflammatory process $^{(40)}$. NF- $\mathrm{KB}$ activation induces insulin resistance by lipid/fatty acid infusion and the inhibition of insulin signalling by lipid metabolites such as diacylglycerol and ceramide ${ }^{(41)}$. In our Western blotting analysis, experimental type 2 diabetes resulted in the increased expression of NF-кBp65, COX-2 and iNOS proteins, whereas the expression of these three proteins was markedly reduced on oligonol administration. Of note, the protein expressions of NF-кBp65, COX-2 and iNOS were fully recovered by oligonol at a concentration of $20 \mathrm{mg} / \mathrm{kg}$ to the levels of $\mathrm{m} / \mathrm{m}$ mice. These results showed that the anti-inflammatory effects of oligonol may be associated with the down-regulation of COX-2 and iNOS followed by the inhibition of NF- $\mathrm{B}$ transcription-stimulated oxidative stress and AGE-RAGE interaction in the kidney of type 2 diabetic mice.

In summary, oligonol treatment in a type 2 diabetic state improves the serum lipid profile (TAG, total cholesterol and NEFA) and renal function. Also, oligonol ameliorates renal abnormalities with lipid dys-metabolism, oxidative stress, excessive formation of AGE and inflammation. Accordingly, oligonol, a supplier of low-molecular-weight polyphenols, may 
reduce the risk of type 2 diabetes by the amelioration of metabolic disorders including dyslipidaemia, oxidative stress, as well as inflammatory responses, in part, by the induction of AGE.

\section{Acknowledgements}

The present study was supported in part by a Grant-in-Aid (C) from the Ministry of Education, Culture, Sports, Science, and Technology, Japan (no. 19500661 to T. Y.). J. S. N., H Y. K., C. H. P. and H. F. conducted the experimental work. T. Y. designed the experiment and wrote the manuscript. The authors declare that there are no conflicts of interest.

\section{References}

1. Poitout V \& Robertson RP (2002) Minireview: Secondary $\beta$-cell failure in type 2 diabetes - a convergence of glucotoxicity and lipotoxicity. Endocrinology 143, 339-342.

2. Prentki M, Joly E, El-Assaad W, et al. (2002) Malonyl-CoA signaling, lipid partitioning, and glucolipotoxicity. Role in $\beta$-cell adaptation and failure in the etiology of diabetes. Diabetes 51, S405-S413.

3. Ahmed N (2005) Advanced glycation endproducts - role in pathology of diabetic complications. Diabetes Res Clin Pract 67, 3-21.

4. Goh SY \& Cooper ME (2008) The role of advanced glycation end products in progression and complications of diabetes. $J$ Clin Endocrinol Metab 93, 1143-1152.

5. Monnier VM, Bautista O, Kenny D, et al. (1999) Skin collagen glycation, glycoxidation, and crosslinking are lower in subjects with long-term intensive versus conventional therapy of type 1 diabetes. Relevance of glycated collagen products versus $\mathrm{HbA}_{1 \mathrm{c}}$ as markers of diabetic complications. Diabetes 48, 870-880.

6. Coughlan MT, Cooper ME \& Thomas MC (2007) Can you reduce your AGE? Strategies to prevent AGE accumulation in diabetes. Drug Discov Today Ther Strateg 4, 85-92.

7. Fujii H, Nishioka H, Wakame K, et al. (2008) Acute, subchronic and genotoxicity studies conducted with oligonol, an oligomerized polyphenol formulated from lychee and green tea extracts. Food Chem Toxicol 46, 3553-3562.

8. Jo EH, Lee SJ, Ahn NS, et al. (2007) Induction of apoptosis in MCF-7 and MDA-MB-231 breast cancer cells by oligonol is mediated by Bcl-2 family regulation and MEK/ERK signaling. Eur J Cancer Prev 16, 342-347.

9. Kundu JK, Chang EJ, Fujii H, et al. (2008) Oligonol inhibits UVB-induced COX-2 expression in HR-1 hairless mouse skin - AP-1 and C/EBP as potential upstream targets. Photochem Photobiol 84, 399-406.

10. Ohno H, Sakurai T, Hisajima T, et al. (2008) The supplementation of oligonol, the new lychee fruit-derived polyphenol converting into a low-molecular form, has a positive effect on fatigue during regular track-and-field training in young athletes. Adv Exerc Sports Physiol 13, 93-99.

11. Sakurai T, Nishioka H, Fujii H, et al. (2008) Antioxidative effects of a new lychee fruit-derived polyphenol mixture, oligonol, converted into a low-molecular form in adipocytes. Biosci Biotechnol Biochem 72, 463-476.

12. Mittal A, Elmets CA \& Katiyar SK (2003) Dietary feeding of proanthocyanidins from grape seeds prevents photocarcinogenesis in SKH-1 hairless mice: relationship to decreased fat and lipid peroxidation. Carcinogenesis 24, 1379-1388.
13. Ali SF, LeBel CP \& Bondy SC (1992) Reactive oxygen species formation as a biomarker of methylmercury and trimethyltin neurotoxicity. Neurotoxicology 13, 637-648.

14. Naito C \& Yamanaka T (1978) Lipid peroxides in atherosclerotic diseases. Nippon Ronen Igakkai Zasshi 15, 187-191.

15. Momose T, Yano Y \& Ohashi K (1963) Organic analysis. XLIV. A new deproteinizing agent for determination of blood sugar. Chem Pharm Bull 11, 968-972.

16. Folch J, Lees M \& Sloane Stanley GH (1957) A simple method for the isolation and purification of total lipides from animal tissues. J Biol Chem 226, 497-509.

17. Mihara M \& Uchiyama M (1978) Determination of malonaldehyde precursor in tissues by thiobarbituric acid test. Anal Biochem 86, 271-278.

18. Hissin PJ \& Hilf R (1976) A fluorometric method for determination of oxidized and reduced glutathione in tissues. Anal Biochem 74, 214-226.

19. Itzhaki RF \& Gill DM (1964) A micro-biuret method for estimating proteins. Anal Biochem 9, 401-410.

20. Tanaka T, Yoshitake N, Zhao P, et al. (2007) Production of oligomeric proanthocyanidins by fragmentation of polymers. Jpn J Food Chem 14, 134-139.

21. Sarni-Manchado P, Le Roux E, Le Guernevé C, et al. (2000) Phenolic composition of litchi fruit pericarp. J Agric Food Chem 48, 5995-6002.

22. Kanda Y, Shimoda M, Tawaramoto K, et al. (2009) Molecular analysis of $d b$ gene-related pancreatic $\beta$ cell dysfunction; evidence for a compensatory mechanism inhibiting development of diabetes in the $d b$ gene heterozygote. Endocr $J \mathbf{5 6}$, 997-1008.

23. Rabe K, Lehrke M, Parhofer KG, et al. (2008) Adipokines and insulin resistance. Mol Med 14, 741-751.

24. Evans JL, Goldfine ID, Maddux BA, et al. (2003) Are oxidative stress-activated signaling pathways mediators of insulin resistance and $\beta$-cell dysfunction? Diabetes 52, 1-8.

25. Niki E, Yamamoto Y, Komuro E, et al. (1991) Membrane damage due to lipid oxidation. Am J Clin Nutr 53, 201S-205S.

26. Tobe K, Suzuki R, Aoyama M, et al. (2001) Increased expression of the sterol regulatory element-binding protein-1 gene in insulin receptor substrate- $2^{-1-}$ mouse liver. $J$ Biol Chem 276, 38337-38340.

27. Wang Z, Jiang T, Li J, et al. (2005) Regulation of renal lipid metabolism, lipid accumulation, and glomerulosclerosis in $\mathrm{FVB}^{d b / d b}$ mice with type 2 diabetes. Diabetes 54, 2328-2335.

28. Ferré $\mathrm{P}(2004)$ The biology of peroxisome proliferator-activated receptors. Relationship with lipid metabolism and insulin sensitivity. Diabetes 53, S43-S50.

29. Park CW, Zhang Y, Zhang X, et al. (2006) PPAR $\alpha$ agonist fenofibrate improves diabetic nephropathy in $d b / d b$ mice. Kidney Int 69, 1511-1517.

30. Baynes JW \& Thorpe SR (1999) Role of oxidative stress in diabetic complications. A new perspective on an old paradigm. Diabetes 48, 1-9.

31. Yan SD, Schmidt AM, Anderson GM, et al. (1994) Enhanced cellular oxidant stress by the interaction of advanced glycation end products with their receptors/binding proteins. $J$ Biol Chem 269, 9889-9897.

32. Koito W, Araki T, Horiuchi S, et al. (2004) Conventional antibody against $N^{\varepsilon}$-(carboxymethyl)lysine (CML) shows cross-reaction to $N^{\varepsilon}$-(carboxyethyl)lysine (CEL): immunochemical quantification of CML with a specific antibody. $J$ Biochem 136, 831-837.

33. Wells-Knecht KJ, Zyzak DV, Litchfield JE, et al. (1995) Mechanism of autoxidative glycosylation: identification of glyoxal and arabinose as intermediates in the autoxidative modification of proteins by glucose. Biochemistry 34, 3702-3709. 
34. Glomb MA \& Monnier VM (1995) Mechanism of protein modification by glyoxal and glycolaldehyde, reactive intermediates of the Maillard reaction. J Biol Chem 270, 10017-10026.

35. Fu MX, Requena JR, Jenkins AJ, et al. (1996) The advanced glycation end product, $N^{\varepsilon}$-(carboxymethyl)lysine, is a product of both lipid peroxidation and glycoxidation reactions. J Biol Chem 271, 9982-9986.

36. Ahmed MU, Frye EB, Degenhardt TP, et al. (1997) $N^{\varepsilon}$-(Carboxyethyl)lysine, a product of the chemical modification of proteins by methylglyoxal, increases with age in human lens proteins. Biochem J 324, 565-570.

37. Csiszar A \& Ungvari Z (2008) Endothelial dysfunction and vascular inflammation in type 2 diabetes: interaction of AGE/ RAGE and TNF- $\alpha$ signaling. Am J Physiol Heart Circ Physiol 295, H475-H476.
38. Evans JL, Goldfine ID, Maddux BA, et al. (2002) Oxidative stress and stress-activated signaling pathways: a unifying hypothesis of type 2 diabetes. Endocr Rev 23, 599-622.

39. Celec P (2004) Nuclear factor $\kappa \mathrm{B}$ - molecular biomedicine: the next generation. Biomed Pharmacother 58, 365-371.

40. Surh YJ, Chun KS, Cha HH, et al. (2001) Molecular mechanisms underlying chemopreventive activities of antiinflammatory phytochemicals: down-regulation of $\mathrm{COX}-2$ and iNOS through suppression of NF- $\mathrm{B}$ activation. Mutat Res 480-481, 243-268.

41. Sinha S, Perdomo G, Brown NF, et al. (2004) Fatty acid-induced insulin resistance in L6 myotubes is prevented by inhibition of activation and nuclear localization of nuclear factor кB. J Biol Chem 279, 41294-41301. 